УДК 343.914

\author{
С. В. Пархоменко \\ Академия Генеральной прокуратуры Российской Федерации, \\ г. Иркутск, Российская Федерация \\ Д. В. Синьков \\ г. Иркутск, Российская Федерация
}

\title{
РАЗВИТИЕ ЗНАНИЙ О ЖЕНСКОЙ ПРЕСТУПНОСТИ И ЕЕ СОВРЕМЕННОЕ СОСТОЯНИЕ В РОССИИ
}

\begin{abstract}
АННОТАЦИЯ. В статье рассматривается вопрос о том, что преступность представляет собой сложное социальное явление, а ее составная часть (женская преступность) отражает общие закономерности и изменения описываемого процесса. До недавнего времени преступному поведению женщин в криминологии не уделялось должного внимания. Так, в начале XX в. данной проблеме было посвящено лишь несколько работ. Однако во второй половине XX в. ситуация изменилась: в научных трудах исследуются количественные и качественные характеристики, освещаются проблемы ее предупреждения. Современное состояние женской преступности, как показало исследование, имеет негативные тенденции в своем развитии - за последние годы увеличился ее удельный вес в структуре преступности в целом, а качественные характеристики рассматриваемого явления приобретают все большую общественную опасность.

кЛЮчЕВЫЕ СЛОВА. Развитие женской преступности; преступность женщин; состояние и структура женской преступности.

ИНФОРМАЦИЯ О СТАТЬЕ. Дата поступления 11 августа 2016 г.; дата принятия к печати 5 сентября 2016 г.; дата онлайн-размещения 30 сентября 2016 г.
\end{abstract}

S. V. Parkhomenko Academy of General Prosecutor's Office of Russian Federation, Irkutsk, Russian Federation

D. V. Sinkov

Irkutsk, Russian Federation

\section{DEVELOPMENT OF KNOWLEDGE OF FEMALE CRIMINALITY AND ITS CURRENT STATE IN RUSSIA}

\begin{abstract}
The article considers the issue of criminality being a complex social phenomenon, and its compound part (female criminality) reflects general regularities and changes of the described process. Until recently, criminal behavior of women was not paid due attention. So, in early XX century only few works were devoted to this problem. Anyhow, in the second part of the XX-th century the situation the situation changed: scientific papers investigate quantitative and qualitative characteristics, highlight the problems of its prevention. The current state of female criminality, as the research shows, has negative trends in its development - the last years have seen an increase of its specific weight in the structure of criminality on the whole, while the qualitative characteristic of this phenomenon is becoming ever more dangerous for the public. KEYWORDS. Development of female criminality; female criminality; state and structure of female criminality.

ARTICLE INFO. Received August 11, 2016; accepted September 5, 2016; available online September 30, 2016.
\end{abstract}

Тема преступности всегда была и остается актуальной, особенно в настоящее время, когда ее массив значителен, а сама преступность приобретает новые формы.

В своих проявлениях преступность разнообразна и многолика. Научный подход к исследованию такого сложного социального явления включает рассмотрение его

\section{Baikal Research Journal}


конкретных разновидностей, к которым относится, в частности, женская преступность. Она отражает общие закономерности преступности и ее изменения, выступая в качестве подсистемы и являясь ее неотделимой частью. В то же время женская преступность обладает спецификой, обусловленной не только социально-биологической особенностью женщин, но и их положением в обществе, выполнением определенных социальных ролей. Рассмотрение отдельных сторон преступности, ее структурных особенностей позволяет более глубоко раскрыть проблему в целом, уточнить факторы, приводящие к совершению преступлений.

До недавних пор ученые-юристы и практические работники правоохранительных органов, ссылаясь на малый удельный вес преступлений, совершаемых женщинами, в общем массиве преступлений не рассматривали данную проблему как самостоятельную. Считалось, что преступления, совершаемые женщинами, не представляют большой общественной опасности и не оказывают заметного влияния на криминогенную и общесоциальную обстановку в стране. Только в последние два десятилетия женская преступность стала формироваться как самостоятельная проблема. Ее появление определяется не только логикой развития науки криминологии, но и потребностями общественной практики, в первую очередь, масштабами и опасными последствиями преступных действий женщин [1, с. 7].

Необходимо заметить, что во многих отраслях современной российской науки, затрагивающих вопросы изучения человеческой личности, не уделяется должного внимания структурному делению исследований по признакам пола. Вопросы, связанные с половой спецификой личности остаются малоисследованными не только в правовом, но и в психологическом, и в педагогическом аспектах.

Многими исследователями недооценивается такой важный физиологический признак человека, как пол, Как правило, это оборачивается тем, что традиционно мужские свойства и принципы поведения невольно принимаются за универсальные, а функциональные, психологические, социальные особенности женщин при исследовании совершенных ими преступлений не учитываются, что, несомненно, сказывается на качестве предупреждения этих преступлений.

Важно заметить, что тема пола впервые стала активно обсуждаться в русской философской мысли в середине XIX в. ${ }^{1}$

Согласно Ю. Рюрикову проблема пола стала социально осознанной относительно недавно, а именно «в последние 100 лет интерес к полу стал всемирным: никогда еще в искусстве, в науке, в публичной жизни он не взлетал так высоко» [2, с. 268]. По его мнению, «этот всемирный интерес - новая и очень сложная проблема, которую выдвинула перед человечеством сама история» [Там же]. Он также отмечает, что «пол человека - это не полчеловека, а весь человек, половое измерение пронизывает все остальные измерения, отпечатывается на всех наших ощущениях, действиях» [3, с. 178$]$.

Заслуживает внимания и утверждение по этому поводу психолога И. С. Кони о том, что «психологическая наука в целом, оставляя возможность отдельному исследователю в рамках своей специальной темы абстрагироваться от половой принадлежности, образования и содержания своих испытуемых и тому подобное, не может полностью игнорировать такое фундаментальное биосоциальное свойство, как пол» $[4$, с. 47].

Академик В. Н. Кудрявцев также обращал внимание на различие половой принадлежности: «есть еще две важные индивидуальные характеристики - пол и возраст индивидов. Казалось бы, что эти абсолютные характеристики исключительно

${ }^{1}$ Русскую «философию пола» представляют такие достаточно разные по своим взглядам мыслители, как философы В. Соловьев и В. Розанов, писатели Л. Толстой и Ф. Достоевский. Позже проблема пола рассматривалась в теории утопического социализма Ш. Фурье, К. А. Сен-Симона и Р. Оуэна.

\section{Baikal Research Journal}

электронный научный журнал Байкальского государственного университета 
биологические. На самом же деле с рассматриваемой точки зрения они тоже имеют социальный эквивалент и должны быть включены в схему по той причине, что быть мужчиной или женщиной - значит выполнять неодинаковые функции в разных социальных системах» [5, с. 303].

В настоящее время многие ученые, представляющие различные отрасли науки и знания, также указывают на необходимость учета половой принадлежности личности при изучении тех или иных социальных явлений (в том числе и преступности). Так, Г. А. Аванесов в своей работе указывает, что «при анализе мужской и женской преступности необходимо учитывать женскую психологию, так как у женщин, по сравнению с мужчинами, не только иная одежда, но и манеры поведения, образ мыслей, даже представление о жизни» [6, с. 454].

Особое внимание на женскую преступность обратил в конце XIX - начале $\mathrm{XX}$ в. русский ученый М. Н. Гернет. В своих трудах он очень подробно анализирует преступления, совершаемые женщинами: кражи, убийства, хулиганство, детоубийство, самогоноварение и т. д. [7;8]. Он анализирует статистические данные о преступности не только дореволюционной России, но и других стран, исследует причины и условия преступности, объясняя их, и при этом отмечает, что в промышленно развитых странах уровень женской преступности выше $[7$, c. 576].

Говоря о женской преступности 10-20-х гг. ХХ в. М. Н. Гернет упоминает, что доля женщин, осужденных за насильственное похищение имущества до войны, не достигала $1,5 \%$, а теперь (1920) колеблется между 4,8 и 9,6 \% [Там же, с. 577]. В конце 20-х гг. ХX в. в целом отмечается снижение женской преступности как в абсолютных цифрах, так и ее удельного веса: в частности, краж с 18,1 \% в 1922 г. до 13,8 \% в 1926 г., грабежей и разбоев - с 7,9 \% в 1923 г. до 5 \% в 1926 г. [Там же].

Изучая структуру и динамику женской преступности, М. Н. Гернет пришел к выводу о том, что в структуре женской преступности в начале XX в. наибольшую часть женщин-преступниц составляют те, кто совершил кражи или участвовал в них, далее идут те, кто совершил убийство. Он одним из первых обратил внимание на прямую зависимость между ростом социальной активности женщин и их преступным поведением. В своих работах он писал: «Чем более жизнь женщины приближается по своим условиям к жизни мужчины, тем более приближается ее преступность размерами к мужской» [9, с. 254]. Кроме этого он наиболее точно подметил специфику женской преступности: «Мужская и женская преступность различается между собой не только своими размерами, но и своим характером. Социальное положение обоих полов отражается в их преступности» [8, с. 136].

В первые годы после Октябрьской революции 1917 г. российская криминология продолжала развиваться. В 20 -е гг. ХХ в. криминология обогатилась большим числом работ по изучению личности преступника [10-12]. Однако к концу 20-х - началу 30 -х гг. в СССР сложилась ситуация, исключающая возможность проведения дальнейших исследований, и лишь в 60-70-х гг. ХХ в. научные исследования в области женской преступности были возобновлены. Появляются публикации, посвященные отдельным аспектам женской преступности, И. А. Кирилловой, Л. Ш. Берекашвили, В. А. Серебряковой [13;14].

В 70-80-х гг. XX в. данным направлением научного исследования занимались Ю. М. Антонян, А. А. Габиани, М. Н. Голоднюк, Н. Ф. Кузнецова, Н. С. Лейкина, А. С. Михлин, Е. В. Середа, Д. А. Шестаков, Т. М. Явчуновская и многие другие [15-21]. В 90-х гг. этого же века Ю. М. Антонян, А. С. Михлин, Е. В. Середа продолжают исследование женской преступности. Некоторые проблемы женской преступности получили освещение в диссертационных исследованиях А. В. Чернышевой, И. В. Корзуна, В. А. Сушко [22-24].

\section{Baikal Research Journal}

электронный научный журнал Байкальского государственного университета 
В настоящее время в научных работах, посвященных женской преступности, исследованы лишь отдельные аспекты этой очень широкой проблемы. В современной женской преступности прослеживаются тенденции, явления и процессы, требующие более глубоко изучения с учетом настоящих реалий.

Преступность женщин отличается от преступности мужчин своими масштабами, характером преступлений и их последствиями, той сферой, в которой они имеют место быть, ролью, которой выполняют при этом женщины, выбором жертвы преступного посягательства, влиянием на их правонарушения семейно-бытовых и сопутствующих им обстоятельств [25, с. 509].

Преступность женщин, представляя собой взаимосвязь образующих ее элементов (определенных видов), их целостность, является относительно самостоятельной системой со специфическими свойствами. Кроме этого, будучи обусловленной общими причинами, женская преступность имеет свои особенности. Они в основном связаны с половыми, психологическими, возрастными и иными отличиями личности преступниц и механизмом их преступного поведения, с проявлением и действием обстоятельств, которые способствуют совершению преступлений женщинами; с динамикой, структурой их преступности, демографическими и многими другими факторами, которые относятся к различным социально-экономическим и нравственно-психологическим сферам общественной жизни. Поэтому всестороннее исследование женской преступности представляет не только научный, но и практический интерес, способствует более целенаправленной и научно-обоснованной организации борьбы с этим явлением.

Все перечисленные обстоятельства приводят нас к выводу о необходимости выделения в общей преступности для самостоятельного криминологического изучения такого ее структурного элемента, как преступность женщин. При этом важным аспектом рассматриваемой проблемы является анализ криминологической характеристики преступности женщин, освещение всего комплекса криминологических вопросов, решение которых способно оказать существенное воздействие на состояние женской преступности, ее предупреждение, выявление и пресечение преступных деяний.

Следует также заметить, что в литературе преступность принято рассматривать как систему социального характера, поскольку она обладает всеми признаками системы [26, с. 46]. Помимо этого, изменения преступности и сама преступность находятся в прямой зависимости от состояния общества, происходящих в нем процессов. Следовательно, возможно и необходимо ее исследовать системно. Так, А. И. Долгова отмечает, что «для преступности характерен комплекс взаимосвязанных элементов. Она обладает определенной структурой. Во взаимодействии со средой преступность может рассматриваться как компонент более широкой или высшей системы (социальной системы общества)» [27, с. 15-16].

Для того чтобы понять и объяснить истоки и закономерности женской преступности, ее необходимо рассматривать в соотношении как сложившийся и неотъемлемый элемент, функционирующий в данное время или в прошлом (а также в будущем) с социальной системой и со всеми элементами общества в целом. Тот факт, что женская преступность в настоящее время является самостоятельной криминологической проблемой, подтверждается ее количественными и качественными показателями.

Состояние криминальной ситуации, связанной с женской преступностью, на сегодняшний день можно охарактеризовать как неблагоприятное. Анализ представленных данных ${ }^{2}$ свидетельствует о том, что на протяжении исследуемого периода

${ }^{2}$ Статистические данные Главного информационного центра Министерства внутренних дел РФ и Судебного департамента при Верховном Суде Российской Федерации.

\section{Baikal Research Journal}

электронный научный журнал Байкальского государственного университета 
тенденция развития женской преступности носит волнообразных характер. При этом в последние годы (2009-2013) отмечается некоторое устойчивое снижение количества выявленных женщин, совершивших преступления. Однако темпы их снижения в 2011-2013 гг. значительно ниже, чем в 2009-2010 гг. (рис. 1). В 2014 г. можно говорить о начале новой волны в развитии данного вида преступности, поскольку количество выявленных женщин-преступниц увеличилось по сравнению с предыдущим годом на $2,5 \%$.

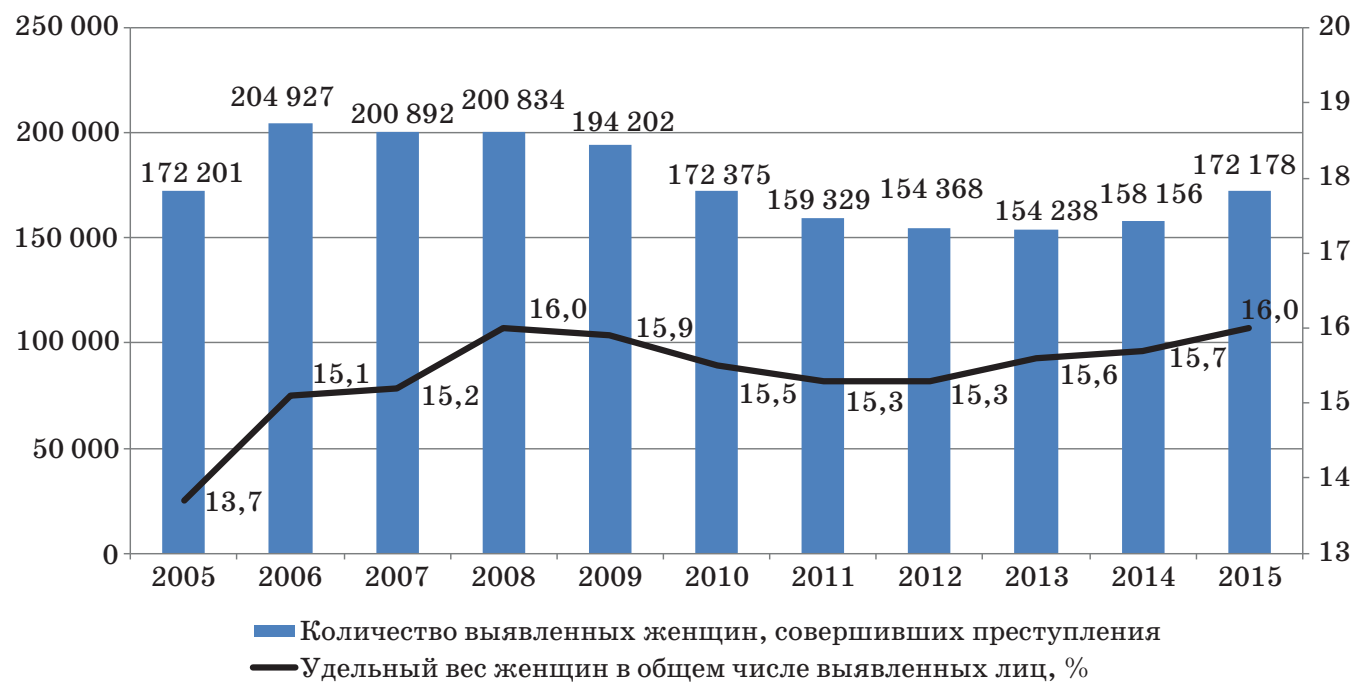

Рис. 1. Состояние женской преступности в Российской Федерации в 2005-2015 г2.

Негативные тенденции в развитии женской преступности подтверждают и относительные показатели. Так, удельный вес выявленных женщин, совершивших преступления на территории Российской Федерации, увеличился с 13,7 \% в 2005 г. до $16,0 \%$ в 2015 г. При этом в 2012-2015 гг. он имел тенденцию к росту. Следует отметить, что данный анализ базируется на статистических данных о выявленных органами внутренних дел лицах, совершивших преступления. При этом за пределами анализа остается латентная (скрытая) часть преступлений, о которых в правоохранительные органы не заявлялось, или которые по тем или иным причинам не были зарегистрированы.

Таким образом, можно отметить, что анализируемые данные не в полной мере отражают состояние женской преступности в полной мере. Исследование данного явления показывает, что оно обладает высоким уровнем латентности, и этот факт также необходимо учитывать.

Анализ структуры женской преступности по видам преступлений в 2015 г. (рис. 2) показал, что ее спектр намного уже, чем мужской, и ее основу в настоящее время составляют преступления корыстной направленности (более 50 \%). Это связывается во многом с занятостью женщин преимущественно в сферах торговли, общественного питания, сбыта и заготовок, т. е. в тех сферах, где и совершаются эти преступления. Каждым четвертым преступлением, совершенным женщинами, является преступление против жизни и здоровья. Можно также отметить, что в последнее время увеличивается общественная опасность последствий от данных преступлений. На третьем месте в структуре женской преступности находятся преступления против здоровья населения и общественной нравственности, и их доля в последние годы незначительно, но увеличивается.

\section{Baikal Research Journal}




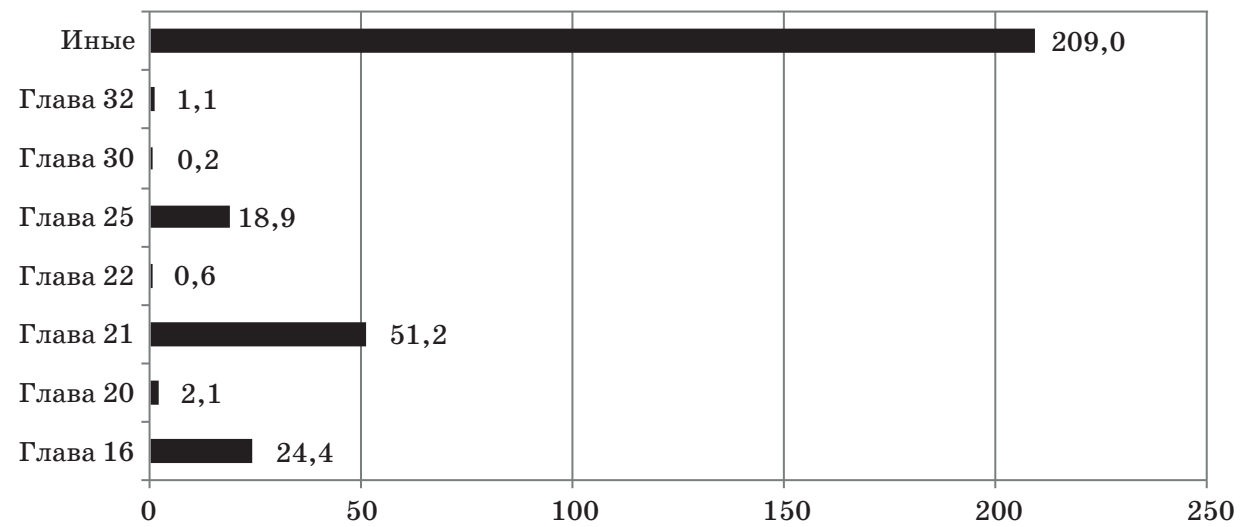

Рис. 2. Структура женской преступности (по главал Уголовного кодекса РФ) в Российской Федерации за 2015 г., \%

Представляется, что ухудшение показателей женской преступности происходит на фоне происходящих кризисных процессов в Российской Федерации в целом и ее регионов в частности, продолжается резкое расслоение общества на малоимущих и богатых людей. В тяжелом положении по уровню доходов находятся работники таких бюджетных сфер, как образование, культура, здравоохранение. Именно в этих сферах большую часть занятых составляют женщины. Иными словами, женщины, будучи наименее защищенными в экономической жизни общества, наиболее часто попадают в сложные жизненные ситуации, которые могут привести их к совершению преступления.

Таким образом, количественные и качественные характеристики женской преступности свидетельствуют о том, что данный вид преступности является сложившимся и неотъемлемым элементом преступности в целом, функционирующим в данное время с социальной системой и со всеми элементами общества в целом. В связи с чем возникает необходимость более детального ее изучения, в том числе и с позиций гендерного подхода.

\section{Список использованной литературы}

1. Антонян Ю. М. Преступность среди женщин / Ю. М. Антонян. - М. : Рос. право, 1992. $-256 \mathrm{c}$.

2. Рюриков Ю. Б. Любовь: ее настоящее и будущее / Ю. Б. Рюриков / Философия любви : в 2 ч. / сост. А. А. Ивин. - М. : Политиздат, 1990. - Ч. 1. - С. 268-330.

3. Рюриков Ю. Б. По закону Тезея / Ю. Б. Рюриков // Новый мир. -1986 . - № 7. C. $187-188$.

4. Кон И. С. Психология половых различий / И. С. Кон // Вопросы психологии. 1981. - № 2 . - С. 47-57.

5. Криминальная мотивация / под ред. В.Н. Кудрявцева. - М. : Наука, 1986. - 302 с.

6. Аванесов Г. А. Криминология и социальная профилактика : учебник / Г. А. Аванесов. - М. : Акад. МВД СССР, 1980. - 526 с.

7. Гернет М. Н. Преступность за границей и в СССР // Избранные произведения / М. Н. Гернет. - М. : Юрид. лит., 1974. - С. 544-595.

8. Гернет М. Н. Моральная статистика. Уголовная статистика и статистика самоубийств : пособие для статистиков и криминалистов / М. Н. Гернет. - М. : Изд. Центр. стат. упр., 1922. - Вып. 1. - 264 с.

9. Гернет М. Н. Преступление и борьба с ним в связи с эволюцией общества // Избранные произведения / М. Н. Гернет. - М. : Юрид. лит., 1974. - С. 203-358.

10. Ходаков Ю. В. Современная преступность женщин / Ю. В. Ходаков // Власть Советов. -1923. - № $10-$ С. 89.

\section{Baikal Research Journal}


11. Укше С. Женщины - корыстные убийцы (социологические характеристики) / С. Укше // Проблемы преступности : сборник / под ред. Е. Ширвиндта, Ф. Трасковича, М. Гернета. - М. ; Л. : Госиздат, 1926. - Вып. 1. - С. 150-172.

12. Родин Д. Преступность мужчин, женщин и несовершеннолетних в 1922 году / Д. Родин // Бюллетень Центрального статистического управления. - 1923. — № 7. - С. $73-79$.

13. Берекашвили Л. Ш. Криминологическая характеристика женщин, совершивших преступления / Л. Ш. Берекашвили, И. А. Кириллова. - М. : Изд-во ВНИИ МВД СССР, 1976. - $44 \mathrm{c}$.

14. Серебрякова В. А. Преступность среди женщин как объект криминологического изучения / В. А. Серебрякова // Вопросы борьбы с преступностью. - М. : Юрид. лит., 1975. Вып. 22. - С. 27-35.

15. Габиани А. А. Преступность среди женщин / А. А. Габиани. - Тбилиси : Сабчота Сакартвело, 1986. - $344 \mathrm{c}$.

16. Голоднюк М. Н. Некоторые вопросы женской преступности / М. Н. Голоднюк // Вестник Московского университета. Сер. 11, Право. - 1978. — № 1. - С. 23-30.

17. Антонян Ю. М. Изучение личности преступника : учеб. пособие / Ю. М. Антонян. М. : Изд-во ВНИИ МВД СССР, 1982. - $80 \mathrm{c.}$

18. Кузнецова Н. Ф. Мотивы преступлений и тенденции их изучения / Н. Ф. Кузнецова // Вопросы советской криминологии : материалы науч. конф. : в 2 ч. - М. : Изд-во Всесоюз. инта по изучению причин и разраб. мер предупреждения преступности, 1975. — Ч. 2. - С. 3-6.

19. Лейкина Н. С. Личность преступника и уголовная ответственность. / Н. С. Лейкина. - Л. : Изд-во Ленингр. ун-та, 1968. - 128 с.

20. Шестаков Д. А. Введение в криминологию семейных отношений / Д. А. Шестаков. Л. : Изд-во Ленингр. ун-та, 1980. - 81 с.

21. Явчуновская Т. М. Влияние алкоголизма как вида психической аномалии на преступность среди женщин / Т. М. Явчуновская // Личность преступника и уголовная ответственность. Правовые и криминологические вопросы : межвуз. науч. сб. - Саратов : Изд-во Сарат. ун-та, 1981. - С. 63-71.

22. Корзун И. В. Криминологическая характеристика и профилактика женской преступности : дис. ...канд. юрид. наук : 12.00 .08 / И. В. Корзун. - М., 1994. - 187 с.

23. Сушко В. А. Совершенствование условий и порядка отбывания наказания в виде лишения свободы осужденными женщинами : дис. ... канд. юрид. наук : 12.00 .08 / В. А. Сушко. - М., 1994. - 192 с.

24. Чернышова А. В. Ресоциализация осужденных женщин, освобожденных из исправительно-трудовых учреждений: правовые и организационные вопросы : дис. ... канд. юрид. наук : 12.00 .08 / А. В. Чернышова. - М., 1991. - 263 с.

25. Криминология : учебник / под ред. В. Н. Кудрявцева В. Е. Эминова. - 2-е изд., перераб. и доп. - М. : Юристъ, 1999. - 509 с.

26. Ли Д. А. Преступность в структуре общества / Д. А. Ли. - М. : Рус. мир, 2000. - 151 с.

27. Долгова А. И. Исходные положения исследования территориальных различий преступности и их причин / А. И. Долгова // Методика изучения территориальных различий преступности и их причин : метод. пособие / под ред. А. И. Долговой. - М. : ВНИИ проблем укрепления законности и правопорядка, 1983. - С. 15-16.

\section{References}

1. Antonyan Yu. M. Prestupnost' sredi zhenshchin [Female criminality]. Moscow, Rossiiskoe pravo Publ., 1992. 256 p.

2. Ryurikov Yu. B. Love: its present and future. In Ivin A. A. (ed.). Filosofiya lyubvi [Philosophy of Love]. Moscow, Politizdat Publ., 1990, pr. 1, pp. 268-330. (In Russian).

3. Ryurikov Yu. B. According to the Theseus Law. Novyi mir $=$ New World, 1986, no. 7, pp. 187-188. (In Russian).

4. Kon I. S. Psychology of sexual differences. Voprosy psikhologii = Issues of Psychology, 1981, no. 2, pp. 47-57. (In Russian).

5. Kudryavtsev V. N. (ed.). Kriminal'naya motivatsiya [Criminal Motivation]. Moscow, Nauka Publ., 1986. 302 p.

6. Avanesov G. A. Kriminologiya i sotsial'naya profilaktika [Criminology and social prevention]. Moscow, Academy of Internal Affairs Ministry of the USSR, 1980. 526 p.

\section{Baikal Research Journal}


7. Gernet M. N. Criminality in abroad and in the USSR. In Gernet M. N. Izbrannye proizvedeniya [Selected Works]. Moscow, Yuridicheskaya literatura Publ., 1974, pp. 544-595. (In Russian).

8. Gernet M. N. Moral'naya statistika. Ugolovnaya statistika i statistika samoubiistv [Moral Statistics. Criminal Statistics and Statistics of Suicides] Moscow, Central statistical Department Publ., 1922. Iss. 1. $264 \mathrm{p}$.

9. Gernet M. N. The crime and the fight against it in the context of evolution of the society. In Gernet M. N. Izbrannye proizvedeniya [Selected Woks]. Moscow, Yuridicheskaya literatura Publ., 1974, pp. 203-358. (In Russian).

10. Khodakov Yu. V. Current female criminality. Vlast' Sovetov = Power of Soviets , 1923, no. 10, p. 89. (In Russian).

11. Ukshe S. Women as mercenary murderers (sociological characteristics). In Shirvindt E., Traskovich F., Gernet M. (eds). Problemy prestupnosti [Problems of criminality]. Moscow, Leningrad, Gosizdat Publ., 1926, iss. 1, pp. 150-172. (In Russian).

12. Rodin D. Criminality of men, female and under-aged in 1922. Byulleten' Tsentral'nogo statisticheskogo upravleniya = Bulletin of Central Statistical Departmrnt, 1923, no. 7, pp. 73-79. (In Russian).

13. Berekashvili L. Sh., Kirillova I. A. Kriminologicheskaya kharakteristika zhenshchin, sovershivshikh prestupleniya [Criminological characteristic of women having committed crimes]. Moscow, All-Soviet Union Ministry of Internal Affairs Publ., 1976. 44 p.

14. Serebryakova V. A. Criminality among women as an object of criminological studies. Voprosy bor'by s prestupnost'yu [Issues of fight against criminality]. Moscow, Yuridicheskaya literatura Publ., 1975, iss. 22, pp. 27-35. (In Russian).

15. Gabiani A. A. Prestupnost' sredi zhenshchin [Female Criminality]. Tbilisi, Sabchota Sakartvelo Publ., 1986. 344 p.

16. Golodnyuk M. N. Some issues of female criminality. Vestnik Moskovskogo universiteta. Seriya 11, Pravo = Moscow University Bulletin. Series 11, Law, 1978, no. 1, pp. 23-30. (In Russian).

17. Antonyan Yu. M. Izuchenie lichnosti prestupnika [Investigation of the criminal's personality]. Moscow, All-Soviet Union Ministry of Internal Affairs Publ., 1982. 80 p.

18. Kuznetsova N. F. Motives of crimes and trends of their studies. Voprosy sovetskoi kriminologii. Materialy nauchnoi konferentsii [Issues of Soviet Criminology. Materials of Scientific Conference]. Moscow, All-Russia Institute of Researching the Causes and Developing the Measures to Counteract Crimes Publ., 1975, pr. 2, pp. 3-6. (In Russian).

19. Leikina N. S. Lichnost' prestupnika i ugolovnaya otvetstvennost' [Personality of the criminal and criminal responsibility]. Leningrad State University Publ., 1968. 128 p.

20. Shestakov D. A. Vvedenie v kriminologiyu semeinykh otnoshenii [Introduction into criminology of family relations]. Leningrad State University Publ., 1980. $81 \mathrm{p}$.

21. Явчуновская T. M. Impact of alcohol, as a kind of psychic anomaly, on criminality among women. Lichnost' prestupnika i ugolovnaya otvetstvennost'. Pravovye i kriminologicheskie voprosy [Personality of the criminal and criminal responsibility]. Saratov State University Publ., 1981, pp. 63-71. (In Russian).

22. Korzun I. V. Kriminologicheskaya kharakteristika i profilaktika zhenskoi prestupnosti. Kand. Diss. [Criminological characteristic and prevention of female criminality. Cand. Diss.]. Moscow, 1994. $187 \mathrm{p}$.

23. Sushko V. A. Sovershenstvovanie uslovii i poryadka otbyvaniya nakazaniya $v$ vide lisheniya svobody osuzhdennymi zhenshchinami. Kand. Diss. [Improving terms and order of service of sentence in form of custodial sentence by convicted women. Cand. Diss.]. Moscow, 1994. $192 \mathrm{p}$.

24. Chernyshova A. V. Resotsializatsiya osuzhdennykh zhenshchin, osvobozhdennykh iz ispravitel'no-trudovykh uchrezhdenii: pravovye i organizatsionnye voprosy. Kand. Diss. [Resocialization of convicted women released from executive-labor institutions: legal and organizational issues. Cand. Diss.]. Moscow, 1991. 263 p.

25. Kudryavtsev V. N., Eminov V. E. (eds). Kriminologiya [Criminology]. $2^{\text {nd }}$ ed. Moscow, Yurist" Publ., 1999. 509 p.

26. Li D. A. Prestupnost'v strukture obshchestva [Criminality in the structure of society]. Moscow, Russkii mir Publ., 2000. 151 p.

\section{Baikal Research Journal}


27. Dolgova A. I. Background of investigating territorial differences of criminality and their causes. In Dolgova A. I. (ed.). Metodika izucheniya territorial'nykh razlichii prestupnosti $i$ ikh prichin [Methods of investigating territorial differences of criminality and their causes]. Moscow, All-Russian Research Institute of Strengthening Legislation and Legal Order Publ., 1983, pp. 15-16. (In Russian).

\section{Информация об авторах}

Пархоленко Светлана Валерьевна - доктор юридических наук, профессор, кафедра уголовно-правовых дисциплин, Иркутский юридический институт (филиал), Академия Генеральной прокуратуры Российской Федерации, 664000, г. Иркутск, ул. Шевцова, 1, e-mail: psvet@mail.ru.

Синьков Длитрий Владимирович - кандидат юридических наук, доцент, г. Иркутск, Российская Федерация, e-mail: dvsv@list.ru.

\section{Authors}

Svetlana V. Parkhomenko - Doctor habil. (Law), Professor, Chair of Criminal and Legal Disciplines, Irkutsk Juridical Institute (branch), Academy of General Prosecutor's Office of Russian Federation, 1 Shevtsov St., 664000, Irkutsk, Russian Federation; e-mail: dvsv@list.ru.

Dmitry V. Sinkov - PhD in Law, Associate Professor, Irkutsk, Russian Federation; e-mail: dvsv@list.ru.

\section{Библиографическое описание статьи}

Пархоменко С. В. Развитие знаний о женской преступности и ее современное состояние в России / С. В. Пархоменко, Д. В. Синьков // Baikal Research Journal. — 2016. — Т. 7, № 5. -

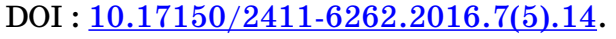

\section{Reference to article}

Parkhomenko S. V., Sinkov D. V. Development of knowledge of female criminality and its current state in Russia. Baikal Research Journal, 2016, vol. 7, no. 5. DOI : 10.17150/24116262.2016.7(5).14. (In Russian).

\section{Baikal Research Journal}

